\title{
Antibacterial and safety tests of a flexible cold atmospheric plasma device for the stimulation of wound healing
}

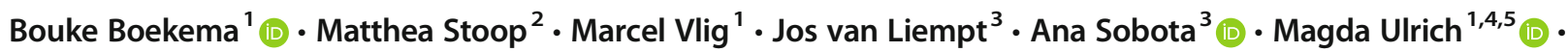 \\ Esther Middelkoop ${ }^{1,2,4}$ (i)
}

Received: 8 October 2020 / Revised: 25 January 2021 / Accepted: 3 February 2021 / Published online: 15 February 2021

(C) The Author(s) 2021

\begin{abstract}
Cold atmospheric plasma (CAP) devices generate an ionized gas with highly reactive species and electric fields at ambient air pressure and temperature. A flexible dielectric barrier discharge (DBD) was developed as an alternative antimicrobial treatment for chronic wounds. Treatment of Staphylococcus aureus in collagen-elastin matrices with CAP for 2 min resulted in a $4 \log$ reduction. CAP treatment was less effective on $S$. aureus on dermal samples. CAP did not affect cellular activity or DNA integrity of human dermal samples when used for up to $2 \mathrm{~min}$. Repeated daily CAP treatments for $2 \mathrm{~min}$ lowered cellular activity of dermal samples to $80 \%$ after 2 to 4 days, but this was not significant. Repeated treatment of ex vivo human burn wound models with CAP for 2 min did not affect re-epithelialization. Intact skin of 25 healthy volunteers was treated with CAP for $3 \times 20$ " to determine safety. Although participants reported moderate pain scores (numerical rating scale 3.3), all volunteers considered the procedure to be acceptable. Severe adverse events did not occur. CAP treatment resulted in a temporarily increased local skin temperature $\left(\approx 3.4^{\circ} \mathrm{C}\right)$ and increased erythema. Lowering the plasma power resulted in a significantly lower erythema increase. Good $\log$ reduction (2.9) of bacterial load was reached in 14/15 volunteers artificially contaminated with Pseudomonas aeruginosa. This study demonstrated the in vitro and in vivo safety and efficacy in bacterial reduction of a flexible cold plasma device. Trial registration number NCT03007264, January 2, 2017
\end{abstract}

\section{Key Points}

- CAP strongly reduced bacterial numbers both in vitro and in vivo.

- Re-epithelialization of burn wound models was not affected by repeated CAP.

- CAP treatment of intact skin was well tolerated in volunteers.

Keywords Dielectric barrier discharge $\cdot$ Skin wound model $\cdot$ Healthy volunteers $\cdot$ Pseudomonas aeruginosa $\cdot$ Methicillin-resistant Staphylococcus aureus (MRSA)

Bouke Boekema

bboekema@burns.nl

1 Association of Dutch Burn Centres, Zeestraat 29, 1941 AJ, Beverwijk, The Netherlands

2 Burn Center, Red Cross Hospital, Beverwijk, The Netherlands

3 Department of Applied Physics, Eindhoven University of Technology, Eindhoven, The Netherlands

4 Department of Plastic, Reconstructive and Hand Surgery, Amsterdam Movement Sciences, Amsterdam UMC, Vrije Universiteit Amsterdam, Amsterdam, the Netherlands

5 Department of Pathology, Amsterdam UMC, Vrije Universiteit Amsterdam, Amsterdam, the Netherlands

\section{Introduction}

The presence of bacteria in a wound can result in delayed healing and a longer hospital stay. Especially burn patients are more susceptible to opportunistic pathogens, such as Pseudomonas aeruginosa and Staphylococcus aureus (Dokter et al. 2016). Because current therapies in burn care still have limited effects in eliminating bacteria, resistance to antibiotics is increasing, and antimicrobial therapies can hamper wound healing; additional measures are required.

In recent years, cold atmospheric plasma (CAP) devices have been tested clinically as an alternative treatment to reduce bacterial load and support wound healing. Various 
plasma devices have been shown to be highly effective against a multitude of bacterial species including clinically relevant pathogens and multidrug-resistant bacterial strains, while buildup of resistance against CAP has not been observed (Daeschlein 2018; Zimmermann et al. 2012). Biological surfaces were however more difficult to disinfect (Maisch et al. 2012; Pavlovich et al. 2013b).

CAP devices for biomedical applications can be divided in two categories based on the technology used to produce plasma. In the first type, plasma is created within the device, which is transported to the treatment site via a carrier gas such as argon. The techniques vary from thin plasma needles to large torches. For the second type, plasma is created by dielectric barrier discharge (DBD) devices at the treatment site in ambient air by applying a high voltage. DBD devices use no counter electrode (surface DBD) or use the body as counter electrode (volume DBD). The antibacterial effects of surface DBDs have been shown in several in vitro studies (Boekema et al. 2016; Ehlbeck et al. 2011; Pavlovich et al. 2013a).

CAP devices, predominantly plasma jets, have been applied to chronic wounds to reduce the bacterial load and stimulate wound healing in vivo but with varying degrees of success (Brehmer et al. 2015; Chuangsuwanich et al. 2016; Daeschlein et al. 2015a; Isbary et al. 2012; Isbary et al. 2010; Isbary et al. 2013b; Klebes et al. 2015; Tiede et al. 2018; Ulrich et al. 2015). Application of the volume DBDbased device PlasmaDerm ${ }^{\circledR}$ on human skin biopsies did not result in cell damage (Awakowicz et al. 2009). Safety and efficacy of this device was tested in a clinical study in patients with venous leg ulcers (Brehmer et al. 2015). Plasma treatment resulted in a significant reduction in the bacterial load of the wounds. Although there were no significant changes in wound size between the two groups, the plasma group showed a larger absolute wound size reduction (non-significant).

Performances of plasma jets and other DBDs were similar, and Assadian et al. concluded in their systematic review that use of atmospheric plasma for chronic wounds is safe (Assadian et al. 2019). Only one severe adverse event (SAE) was reported in 9 studies with 268 patients, which was unrelated to plasma (shifted vertebra) (Brehmer et al. 2015). Most reported adverse events (AEs) were minor sensation of burning or heat, tingling or prickling and tautness of skin. These sensations were absent shortly after ceasing plasma treatment.

Unlike plasma jets and other DBDs, the volume DBD in the present study (PLASOMA prototype) generates plasma in the wound in a closed system. The creation of plasma is accompanied by an electric current in the skin and by electromagnetic fields that can stimulate blood vessel formation and cell proliferation ( $\mathrm{Li}$ et al. 2012). The volume DBD has been tested in 20 patients with diabetic foot ulcers (DFU) (Peters et al. 2017). Wounds received 10 treatments in 2 weeks with $3 \times 20$ s plasma and $2 \times 20$-s intervals with plasma off. Bacterial load of $S$. aureus was significantly reduced after
CAP application. Fifty-five percent of the patients reported transient and mild AE; SAE related to the treatment did not occur. However, many of these patients probably had limited feeling in their feet due to neuropathology associated with DFU (Volmer-Thole and Lobmann 2016). In burns on the other hand, acute pain is an important complication. Burn patients can experience procedural pain during wound care procedures such as during dressing changes, which is difficult to control (van Loey, personal communication, February 11, 2020). In addition, burn patients suffer background pain, which varies greatly in intensity, is experienced at rest and can be caused by inflammation. Therefore, before exposing burn patients to possible additional pain caused by plasma treatment, we tested safety and efficacy on intact skin of healthy human volunteers. We also tested safety and efficacy of the PLASOMA prototype in vitro on bacteria and dermal tissue to answer the question: Can bacterial load be reduced with a flexible volume DBD device without causing damage to cells in wounds?

\section{Materials and methods}

\section{Plasma device}

Plasma power source and pads were provided free of charge by Plasmacure (Nijmegen, the Netherlands) (Fig. 1). Plasma is generated in pads made of flexible material. For the reference electrode, a standard ECG patch was used (red dot, 3M Health Care, Germany). The driving unit can only operate when proper connection of the pad is detected. Plasma is only created when the pad makes contact with the subject's body. To further protect the subject, plasma treatment is stopped automatically in case a threshold current or voltage is reached. Plasma was generated at a high and a low power setting.

\section{Ozone measurements}

Ozone density was determined by absorption spectroscopy at $266 \mathrm{~nm}$, using an Nd:YAG laser (ULTRA CFR Nd:YAG Laser System) coupled through optical fibres and collimated using quartz lenses (Gorshelev et al. 2014). The pad was placed on a steel mesh with openings of approximately $1 \mathrm{~mm}$ that was grounded, creating plasma between the pad and the mesh. The light path was positioned approximately $2 \mathrm{~mm}$ above the mesh, in a closed cylinder $30 \mathrm{~mm}$ in diameter (the size of the active area of the pad) and 4-mm thick. The absorption path was therefore 30-mm long. Plasma was generated at high power setting, with $4 \%$ difference in the voltage amplitude. 
Fig. 1 a The plasma device consisting of the plasma driving unit (plasma pulser) and plasma pad; b plasma pad with scale in $\mathrm{cm}$. Plasma pad showing the side with prefabricated holes that is in contact with the skin; $\mathbf{c}$ plasma is generated in the small holes; $\mathbf{d}$ schematic diagram of device for the treatment of samples on chicken meat as a support layer; layers of human skin $(0.7 \mathrm{~mm})$ were used to increase the distance between sample and plasma; $\mathbf{e}$ schematic diagram of device during treatment of healthy volunteers. $\mathrm{HV}$, high voltage; CEM, collagen elastin matrix

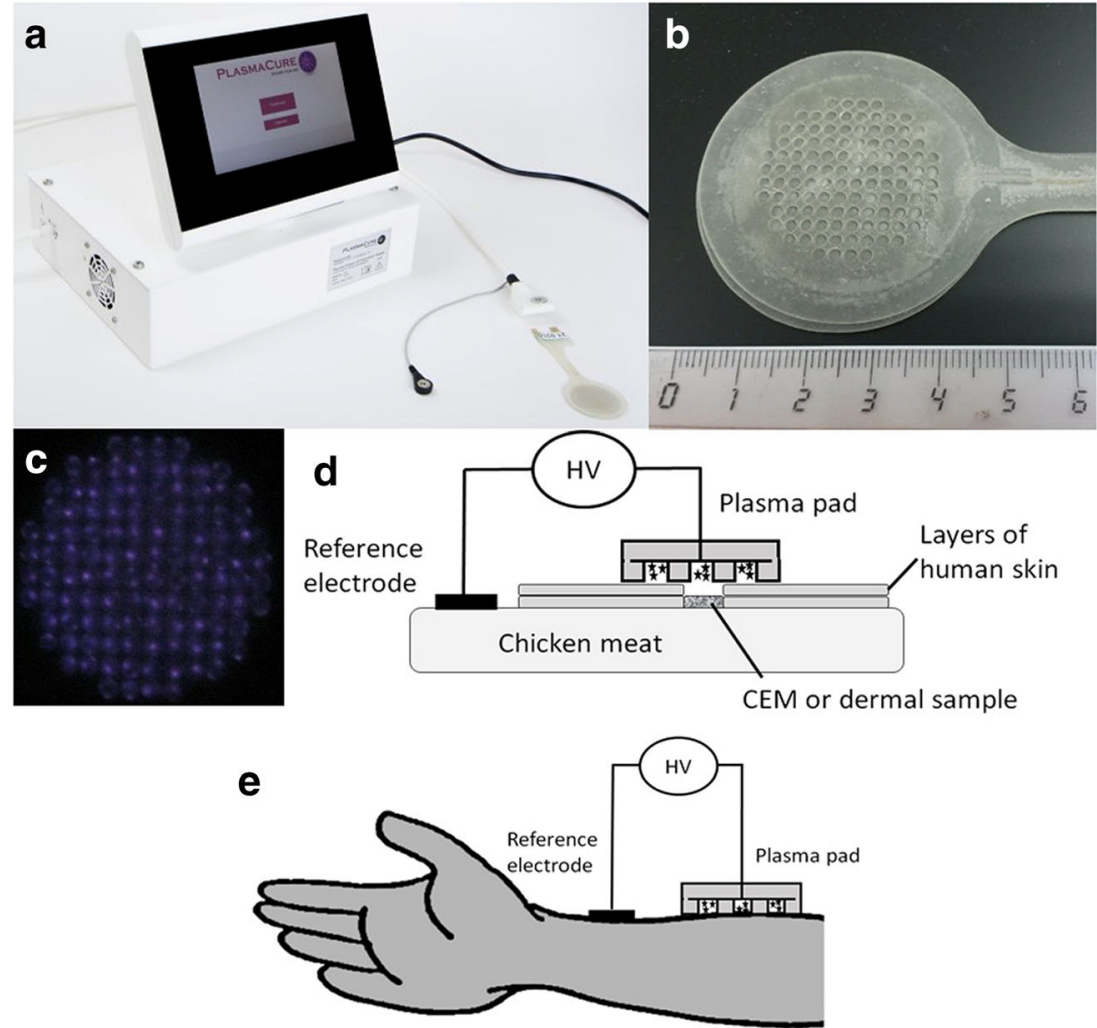

Plasma treatment in vitro

\section{Human skin}

Human skin was obtained from healthy donors undergoing dermolipectomy or from deceased donors via the Euro Tissue Bank, after obtaining consent according to institutional guidelines. Split-thickness skin grafts ( 0.7 or $1 \mathrm{~mm}$ thickness) were harvested using a dermatome.

\section{Bacterial culture and quantification}

P. aeruginosa (strain PAO1, ATCC BAA47, culture collection NCCB 2452, obtained from J. Tommassen, UU, the Netherlands) and $S$. aureus (Methicillin-resistant $S$. aureus (MRSA), strain LUH14616, culture collection NCCB 100829, obtained from P. Nibbering, LUMC) were routinely cultured on Luria-Bertani broth (LB, Invitrogen, Paisley, UK) agar at $37^{\circ} \mathrm{C}$. Bacteria from a proliferating or logarithmic culture in $5 \mathrm{ml} \mathrm{LB}$ were diluted in $0.85 \% \mathrm{NaCl}$ to the required colony forming units $(\mathrm{CFU}) / \mathrm{ml}$, based on $\mathrm{OD}_{600}$. To determine bacterial numbers, collagen-elastin matrices, dermal samples or the viscose ends of swabs were placed in a vial with $1 \mathrm{ml}$ PBS and a metal bead and were placed in a TissueLyser LT (Qiagen, Venlo, The Netherlands) for $4 \mathrm{~min}$ at $45 \mathrm{~Hz}$ (Boekema et al. 2013). Bacterial suspensions were serially diluted and plated on agar plates: LUH14616 on LB agar and PAO1 on selective Pseudomonas Isolation Agar (Oxoid) plates supplemented with $0.25 \%$ Cetrinix (Sigma, St. Louis, MO) (PIA-CN).
Bacterial solutions $\left(10 \mu \mathrm{l}, 10^{5} \mathrm{CFU}\right)$ were pipetted on dry porous collagen-elastin matrices (CEM, Ø $15 \mathrm{~mm}, 1 \mathrm{~mm}$ thickness); CEM prewetted with $100 \mu \mathrm{l} 0.85 \% \mathrm{NaCl}$ or on skin (Ø $15 \mathrm{~mm}, 1 \mathrm{~mm}$ thickness, dermal side). These samples were placed on agar, metal or chicken meat to which the reference electrode was connected. Chicken meat represented tissue that is present underneath wounds. To mimic the in vivo situation, ex vivo human skin with a hole $(\varnothing 15 \mathrm{~mm})$ was placed around the samples (Fig. 1d). Plasma pads were placed on top of the samples. Layers of the skin were added to increase the distance between CEM and plasma pad from 0 to $0.7 \mathrm{~mm}$ and $1.4 \mathrm{~mm}$ to simulate deeper wounds. After plasma treatment at low power setting, samples were processed for bacterial quantification. The log reduction (LR) was calculated: $\mathrm{LR}=\log$ CFU before $-\log$ CFU after treatment.

Similarly, human skin biopsies (Ø $15 \mathrm{~mm}, 1 \mathrm{~mm}$ thickness) were treated. Three punch biopsies $(\varnothing 4 \mathrm{~mm})$ were taken for viability assessment.

\section{Viability assays}

To estimate tissue viability after treatment, MTT assays were performed (Coolen et al. 2010). Immediately after plasma treatment of dermal samples at low power setting, biopsies (4 mm) were taken and transferred to 24 -well plates with 
$2 \mathrm{ml}$ Dulbecco's Modified Eagle Medium (DMEM) supplemented with $10 \%(\mathrm{v} / \mathrm{v})$ foetal calf serum (FCS), $1 \%(\mathrm{v} / \mathrm{v})$ penicillin/streptomycin $(\mathrm{P} / \mathrm{S})$ and $1 \%$ GlutaMAX (all from Gibco, Paisley, UK) further referred to as fibroblast medium (FBM), containing $2 \mathrm{mg} / \mathrm{ml}$ MTT (3-(4.5-Dimethylthiazol-2yl)-2.5-diphenyltetrazolium bromide). Samples were incubated with MTT medium for $3 \mathrm{~h}$ at $37^{\circ} \mathrm{C}, 5 \% \mathrm{CO}_{2}$. Formazan was dissolved by shaking skin samples in the presence of $1 \mathrm{ml}$ DMSO and a metal bead during $4 \mathrm{~min}$ at $50 \mathrm{~Hz}$ (TissueLyser). The resulting supernatant was quantified in a spectrophotometer $\left(\mathrm{OD}_{560}-\mathrm{OD}_{650}\right.$, SpectraMAX, Molecular Devices). Results were expressed relative to untreated controls (in \%). For repeated treatments, skin samples were incubated inbetween treatments in $\mathrm{FBM}$ at $37^{\circ} \mathrm{C}, 5 \mathrm{CO}_{2}$ for $24 \mathrm{~h}$.

\section{Burn wound model}

To determine the effect of plasma on wound healing, an ex vivo human skin model was used (Boekema et al. 2013). Split-thickness skin grafts $(0.7 \mathrm{~mm}$ thickness $)$ were cut into $1.25 \mathrm{~cm}^{2}$ pieces. Burn wounds were created with a copper device $(2 \times 10 \mathrm{~mm})$ attached to a soldering iron $\left(95^{\circ} \mathrm{C}\right.$, applied for $10 \mathrm{~s})$. This would correspond to a full-thickness burn. The burned wound models (BWMs) were placed epidermis up on stainless steel grids and were cultured air exposed at $37^{\circ} \mathrm{C}$ with 5\% $\mathrm{CO}_{2}$ using DMEM/ Ham's F12 (3:1) supplemented with $2 \%(\mathrm{v} / \mathrm{v}) \mathrm{P} / \mathrm{S}, 2 \%$ (v/v) FCS (Gibco), $1 \mu \mathrm{M}$ hydrocortisone, $1 \mu \mathrm{M}$ isoproterenol, $0.1 \mu \mathrm{M}$ insulin, $1 \mu \mathrm{M} \mathrm{L}$-carnitine, M L-serine, $1 \mu \mathrm{M}$ DL-alpha-tocopherol, $130 \mu \mathrm{g} / \mathrm{ml}$ ascorbic acid, a lipid supplement containing $25 \mu \mathrm{M}$ palmitic acid, $15 \mu \mathrm{M}$ linoleic acid, $7 \mu \mathrm{M}$ arachidonic acid (all from Merck $\mathrm{KGaA}$ ) and $24 \mu \mathrm{M}$ BSA (Thermo Fisher Scientific).

Metal grids with BWMs were placed on a metal surface, which was connected to the reference electrode. Plasma treatments at low power setting were applied for 1 or $2 \mathrm{~min}$ on the BWMs, and treatments were repeated on days 3, 7 and 10 . Controls consisted of untreated BWMs. Samples were kept in culture for up to 2 weeks. Twenty-four hours before fixation of BWMs in kryofix (50\% ethanol and 3\% PEG300), $20 \mu \mathrm{M}$ 5-bromo-2-deoxyuridine (BrdU) (Merck KGaA) was added to the culture medium.

\section{Histology}

Skin samples were processed for paraffin embedding. Sections $(5 \mu \mathrm{m})$ were deparaffinized and rehydrated for haematoxylin and eosin (H\&E) staining, using standard techniques. Sections from BWMs were stained for BrdU (MP Biomedicals, Illkirch, France) (Coolen et al. 2010). Antigen retrieval consisted of incubation in $10 \mathrm{mM}$ sodium citrate solution for $20^{\prime}$ at $65^{\circ} \mathrm{C}(\gamma \mathrm{H} 2 \mathrm{AX})$ or in $2 \mathrm{M} \mathrm{HCl}$ for $30^{\prime}$ at room temperature followed by $0.1 \mathrm{M}$ Borax $\mathrm{pH} 8.5$ (twice 5') and $7^{\prime}$ in $0.5 \%$ Triton-X 100 in PBS (BrdU). Brightvision poly HRP-Anti-Mouse IgG and Bright-DAB Solution (Immunologic, Duiven, the Netherlands) were used for visualization. The newly formed epidermis was measured with digital image analysis (NIS Elements Ar software, Nikon, Amsterdam, the Netherlands). To monitor double strand breaks, sections were stained with an antibody against phosphorylated $\gamma$ H2AX (MA1-2022, Thermo Fisher Scientific) followed by Alexa Fluor ${ }^{\circledR}$ 555-conjugated goat-anti-mouse antibody (Molecular Probes, Thermo Fisher Scientific) and DAPI (Sigma) (Isbary et al. 2013a).

\section{Trial design and demographics}

We performed an interventional safety study with intraindividual comparison. The study protocol was approved by the regional ethics committee of Noord-Holland, the Netherlands (reference number M016-046), registered at clinicaltrials.gov (registration number NCT03007264, January 2, 2017). The study followed the tenets of the Declaration of Helsinki (52nd World Medical Association General Assembly, Edinburgh, Scotland, October 2000). A total of 25 healthy subjects were included from the general public; informed consent was obtained. Exclusion criteria were skin disease, infected wounds, implanted electrical medical devices, (possible) pregnancy, life-threatening cardiac conductivity abnormality and active malignancy. A research nurse assisted the procedures. Sixty percent of volunteers were male, average age was $58 \pm 12$ years and Fitzpatrick skin type 3 was most prevalent (56\%) (Table S1). Subjects were randomly divided over 3 groups: (A) plasma at high power, (B) bacteria and plasma at high power and (C) bacteria and plasma at low power.

\section{Pain measurement}

Pain scores were determined on a numerical rating scale (NRS) of 0-10. A pain score less than 4 is considered acceptable pain (de Jong et al. 2015), a pain score between 4 and 7 is moderate-severe pain and above 7 severe pain. Subjects were asked to qualify the experienced pain as acceptable or not.

\section{Skin temperature}

Thermal images (as shown in Figure S1) were produced using the FLIR ONE camera (FLIR Systems, Inc., Wilsonville, OR, USA) attached to an iPad mini (Apple Inc., Cupertino, CA, USA). The mean temperature of the reference area (wrist) was subtracted from the mean temperature of the area of interest (inner forearm) and was expressed as $\mathrm{dT}\left({ }^{\circ} \mathrm{C}\right)$ (Jaspers et al. 2017a). Subsequently, dT at baseline (before treatment) was subtracted from dT after treatment yielding a change in temperature due to treatment. 


\section{Skin colour measurement}

Skin colour was measured by means of the DermaSpectrometer ${ }^{\circledR}$ (Cortex Technology, Hadsund, Denmark). This reliable narrowband spectrometer generates an erythema index based on the differences in light absorption of red haemoglobin (Draaijers et al. 2004).

\section{Skin barrier function}

Skin barrier function was evaluated by measuring TEWL (Tewameter® TM300 probe, Courage \& Khazaka GmbH, Cologne, Germany). TEWL estimates the flux density of evaporated water from the skin surface (Tagami and Yoshikuni 1985) and is considered an important physiological characteristic to assess the function of the skin barrier (Rogiers 2001).

\section{Treatment of volunteers}

Baseline measurements were performed on both inner forearms for all subjects (Figure S1). Water resistant pen was used to mark the areas for the pads on both arms.

For group A, plasma pads were placed on both arms and were secured with Microfoam surgical tape (3M); ECG patches (3M red dot, $3 \mathrm{M}$ ) were placed on the right arm next to the pad to connect the reference electrode. Plasma treatments were applied (high power setting) on the right arm: 3 times for $20 \mathrm{~s}$ with plasma on separated by 2 intervals for $10 \mathrm{~s}$ with plasma off. The contralateral arm was treated exactly the same except plasma was not applied. One pad was used per arm, and pads were not changed between intervals. Pads and reference electrode were removed directly after treatment. Measurements were done immediately after treatment and after $30 \mathrm{~min}$.

For group B and C, $15 \mu \mathrm{l}$ of bacterial suspension (PAO1, $10^{7} \mathrm{CFU} / \mathrm{ml}$ ) was applied on the area of interest on both arms and left to dry for a few minutes. Plasma pads and ECG patches were placed as in group A. Plasma treatments were applied 3 times for $20 \mathrm{~s}$ with plasma separated by 2 intervals for $10 \mathrm{~s}$ with plasma off, at high (group B) or low power setting (group C). Pads and reference electrode were removed directly after treatment, and thermal images were taken instantly and after $30 \mathrm{~min}$. The scrub wash method (Taylor et al. 2003) was used to collect all surviving bacteria, using a swab and 3 times $0.5 \mathrm{ml}$ Dulbecco's Phosphate-Buffered Saline (PBS, Gibco®; Thermo Fisher Scientific, Etten-Leur, the Netherlands), $0.1 \%$ Triton X-100 (Lademann et al. 2012; Li et al. 2013). Skin was disinfected with $70 \%$ alcohol and dried. Measurements for erythema and TEWL were done immediately after this and after $30 \mathrm{~min}$. The log reduction (LR) per subject was calculated:

$\mathrm{LR}=\log$ CFU before $-\log$ CFU after treatment.

All subjects were contacted after approximately 1 week to check for any potential adverse events.

\section{Statistics}

Statistical analysis was performed with SPSS (Version 16.0 for MS Windows, SPSS Inc., Chicago, IL). The MannWhitney $U$ (MWU) test was used to determine significant differences due to CAP treatment or between groups. Wilcoxon matched-pairs signed-rank test (WMP) was used for paired samples (e.g. intra-individual comparison). Results of MTT assays were expressed relative to their respective untreated controls before averaging to circumvent donor variations. Volunteer characteristics sex and skin type were compared using the chi-square test for categorical data.

\section{Results}

A flexible DBD plasma pad was developed to enable treatment of curved surfaces. Here we report the bactericidal and safety effects of in vitro tests. An interventional study on intact skin of human volunteers was conducted to study safety and efficacy in vivo.

\section{Bactericidal efficacy in vitro}

Initial tests were performed with bacteria spread on agar plates. These tests showed that the volume DBD pad inactivated bacteria effectively after short treatment times (< 2 min, data not shown). To simulate the wound environment and for a better quantification of the bactericidal effect, we tested the plasma pads on bacteria in a 3D-collagen/elastin matrix (CEM, Ø $15 \mathrm{~mm}, 1 \mathrm{~mm}$ thickness). Collagen and elastin are major components of the dermis. CAP treatment of bacteria in dry CEM also resulted in high reduction (log 4 reduction) after $<2$ min treatment (data not shown).

To mimic the in vivo wound situation even more, CEMs were placed on chicken meat, while human skin was placed around the CEM (see Fig. 1e). Plasma treatment reduced the bacterial load from $\log 4.7$ to $<\log 1$ when bacteria were added to dry CEM (Fig. 2a). Bacterial reduction was dependent on plasma treatment time. In larger wounds with varying depths, the plasma pad might not always make contact to the entire surface of the wound. This was simulated by adding layers of skin $(0.7 \mathrm{~mm}$ thickness) to increase the distance between CEM and plasma pad (Fig. 1d). The plasma pads were equally effective on bacteria at 0 to $1.4 \mathrm{~mm}$ (Fig. 2a). Because the wound environment is moist, the effect of a higher water content was tested. When plasma was applied to bacteria present in CEM with a higher water content $(110 \mu \mathrm{l})$, the bactericidal effect was significant in specific conditions but was reduced in general (Fig. 2b). A similar approach was used to determine the bactericidal effect of plasma on samples of human dermis (Ø $15 \mathrm{~mm}$ ). The bactericidal effect was however strongly reduced on dermal samples (Fig. 2c). 
a MRSA in dry collagen matrix

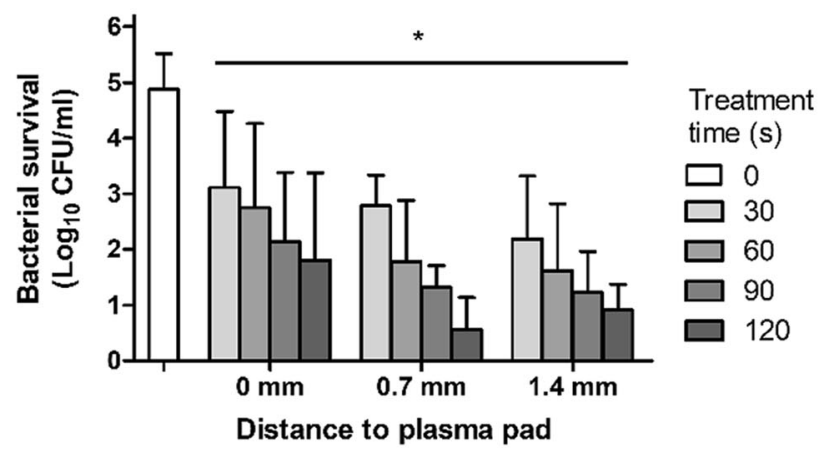

b MRSA in wet collagen matrix

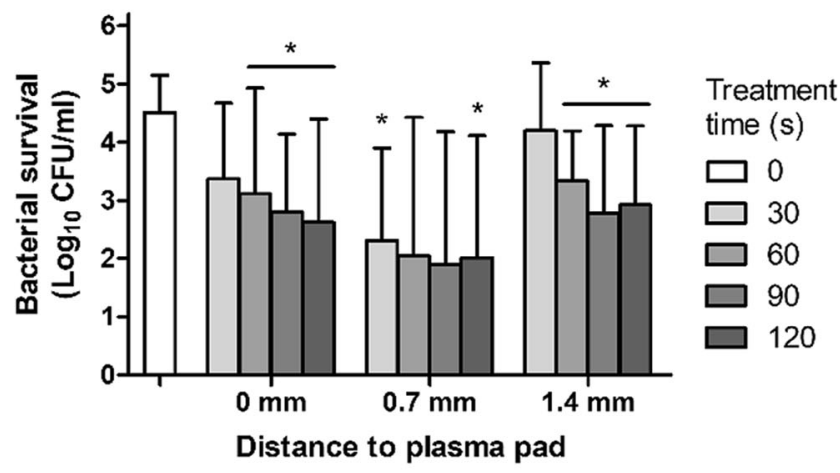

C

MRSA on dermis

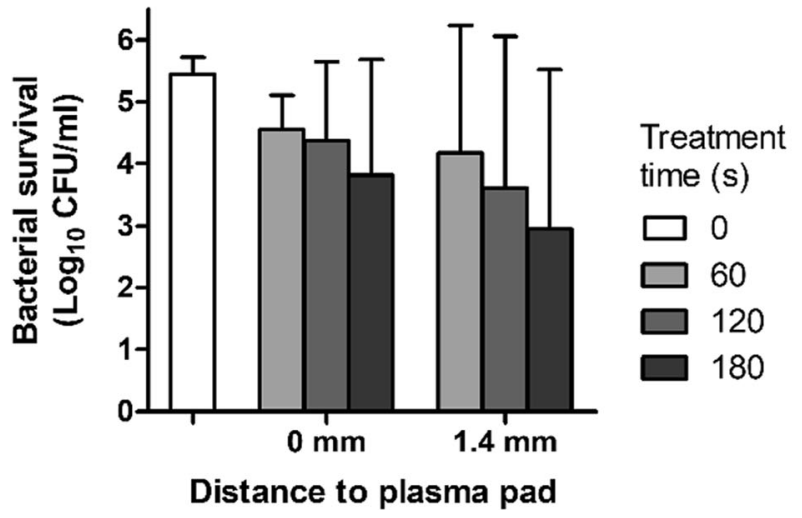

Fig. 2 Surviving bacteria after plasma treatment of $10 \mu$ MRSA strain LUH14616 (a) in dry CEM ( $n=6$ in duplicate), (b) in wet CEM ( $n=5$ in duplicate) or (c) on human dermis ( $n=3-6$ in duplicate). All samples were placed on chicken meat; human skin was placed around them. Distance between plasma pad and tissue was increased by adding layers of skin surrounding the CEM. Mean values and standard deviation are shown. * Significant difference compared to untreated control samples $(0 \mathrm{~s})$, $p<0.05$ (MWU).

\section{Safety tests in vitro}

For safety assays, a similar setup was used. Dermal samples were placed on chicken meat, while human skin was placed around the sample to mimic the in vivo situation (Fig. 1e). Dermal samples were chosen because in wounds the epidermis is (mostly) absent. More layers of skin ( $0.7 \mathrm{~mm}$ thickness) were added to increase the distance between dermal sample and plasma pad. Samples were CAP treated, and cellular activity was determined (MTT) as a measure of cell viability (Fig. 3a). Viability of these samples was not reduced by CAP treatments of up to $90 \mathrm{~s}$ for all tested distances to the plasma. CAP treatment for $120 \mathrm{~s}$ slightly reduced activity at 0 and $0.7-\mathrm{mm}$ distance $(p<0.05)$.

Since potentially multiple treatments will be given to patients, we tested repeated treatments on dermal samples. Dermal samples received plasma treatments of 60 or $120 \mathrm{~s}$ on consecutive days and were incubated in-between in medium at $37^{\circ} \mathrm{C}, 5 \% \mathrm{CO}_{2}$. Viability was decreased after 2 and 4 daily CAP treatments to $80 \%$ (non-significant, Fig. 3b).

Because plasma might affect DNA integrity (Wu et al. 2013), we evaluated phosphorylation of $\gamma \mathrm{H} 2 \mathrm{AX}$, which is involved in repair of double-strand breaks (Kuo and Yang
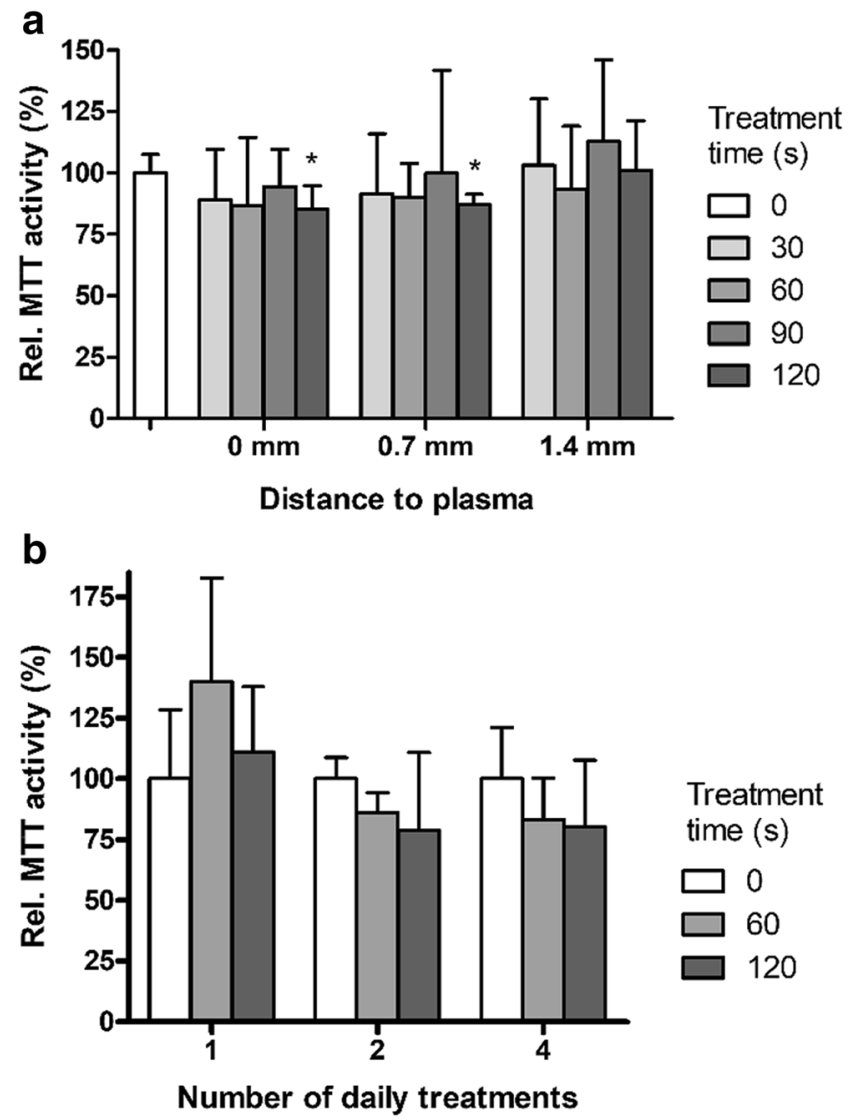

Fig. 3 a Effect of CAP on cellular activity of human dermis $(\varnothing 15 \mathrm{~mm}$, $1 \mathrm{~mm}$ thickness) placed on chicken meat. Distance between plasma and tissue was increased by adding layers of skin surrounding the dermal samples. Plasma was applied for the indicated times. Cellular activity was measured with MTT in 3 punch biopsies $(\varnothing 4 \mathrm{~mm})$ and is expressed as relative to the untreated controls (in \%). Mean values and standard deviation are shown ( $n=4-7$ in duplicate). b Effect of repeated CAP treatment on cellular activity of human dermis measured with MTT. Plasma was applied on consecutive days for the indicated times in the $x$ axis. Dermal samples were incubated in $\mathrm{FBM}$ at $37^{\circ} \mathrm{C}, 5 \% \mathrm{CO}_{2}$. Mean values and standard deviation are shown $(n=3-5$ in triplicate). * Significant difference, $p<0.05$ (WMP) 
2008). Dermal samples were plasma treated for 60 or $120 \mathrm{~s}$ and were processed for immunohistochemistry (Fig. 4a). The number of positive nuclear foci were counted and corrected for the total number of nuclei. Plasma treatment did not show more $\gamma \mathrm{H} 2 \mathrm{AX}$ positive cells compared to untreated control samples (Fig. 4b).

To monitor the effect of plasma treatment on wound healing, we treated burn wound models consisting of ex vivo human skin for 60 or $120 \mathrm{~s}$, for four times in 10 days. Repeated plasma treatment did not affect re-epithelialization or the number of proliferative keratinocytes in the neo-epidermis (Fig. 4c).

Although in vitro tests demonstrated safety of CAP for tissues and wound healing, heat generated by CAP might pose a problem when treating human subjects. We measured the temperature of ex vivo skin (placed on metal) and plasma pad directly after CAP treatment. To limit the buildup of heat, the plasma treatment was divided in three periods of $20 \mathrm{~s}$ separated by intervals of $20 \mathrm{~s}$ with plasma off. Temperature of the plasma pad increased with treatment time (Fig. 5). As a result, the average ex vivo skin temperature increased with $9^{\circ} \mathrm{C}$ after 3 times $20 \mathrm{~s}$ of plasma treatment. To investigate whether increasing plasma power affects warming of the skin, two settings were tested. Although the high plasma power setting significantly increased temperature of the plasma pad after the first and second period, it did not significantly affect the increase in skin temperature.

\section{Ozone density}

Ozone density measurements were performed using plasma treatment divided in three periods of $20 \mathrm{~s}$ separated by 2 intervals of $60 \mathrm{~s}$ with plasma off. During successive plasma periods of $20 \mathrm{~s}$, ozone is generated at a concentration up to 600 ppm (Fig. 6). The ozone concentration drops between successive periods, but the gas mixture requires more than $60 \mathrm{~s}$ to revert back to its original state before the treatment. Successive measurements with shorter plasma off intervals showed the same trend of decrease in ozone density between periods and no increase in the peak ozone concentration.

\section{Safety tests in healthy volunteers}

Because good results were obtained with the in vitro tests of CAP treatment, we conducted a clinical trial. Since CAP may elicit some pain, we tested safety of CAP in healthy volunteers. A total of 25 healthy volunteers divided over 3 groups

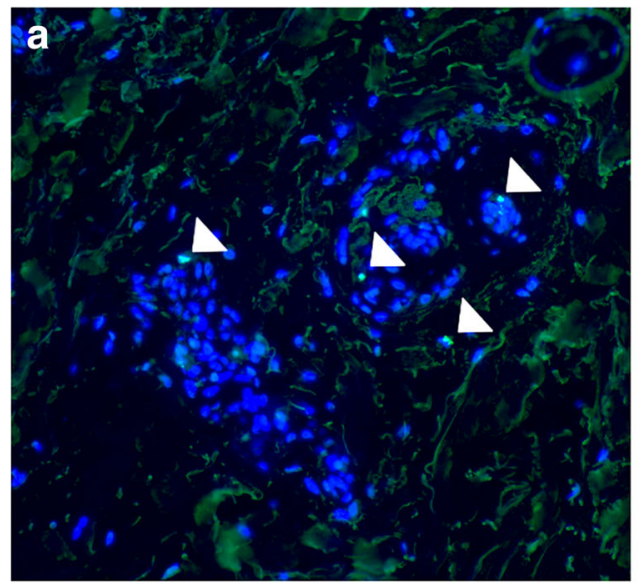

b

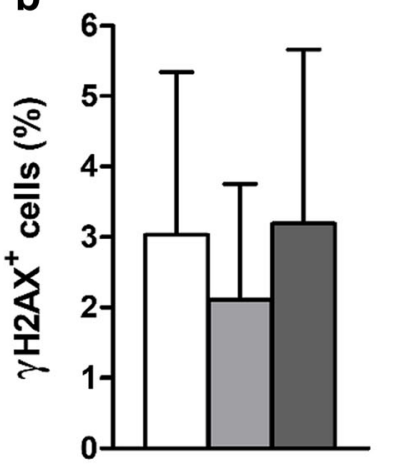

C

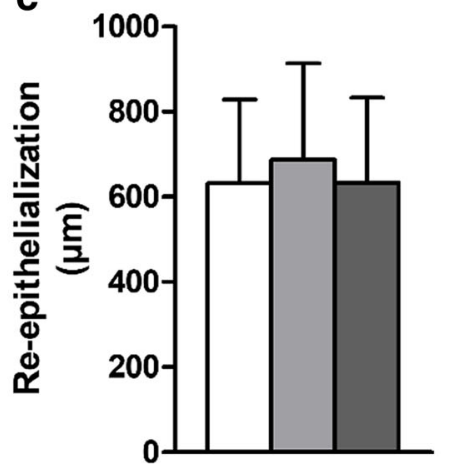

d

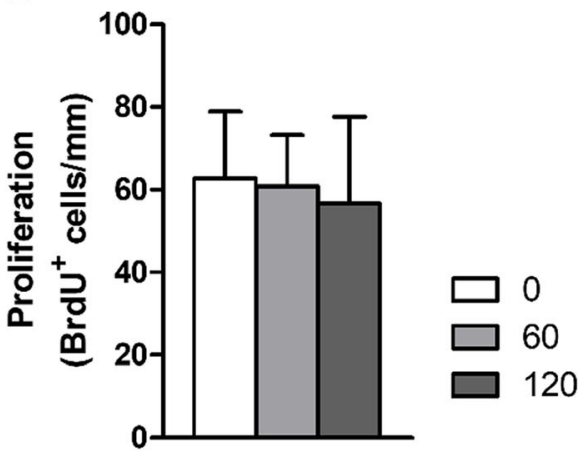

Fig. 4 a Example of dermal sample after plasma treatment, stained for $\gamma \mathrm{H} 2 \mathrm{AX}$. Positive nuclei are indicated (arrow head); bar is $50 \mu \mathrm{m}$. b Quantification of the relative number of cells (\%) positive for $\gamma \mathrm{H} 2 \mathrm{AX}$ after plasma treatment of dermal tissue ( $n=4-5$ in duplicate). c Re- epithelialization and $\mathbf{d}$ proliferation of keratinocytes in BWM after 2 weeks of culture. Plasma was applied four times in 10 days. Mean values and standard deviation are shown ( $n=6$ for 0 and $120 \mathrm{~s}, n=4$ for $60 \mathrm{~s}$, all in duplicate). Significant differences were not observed 


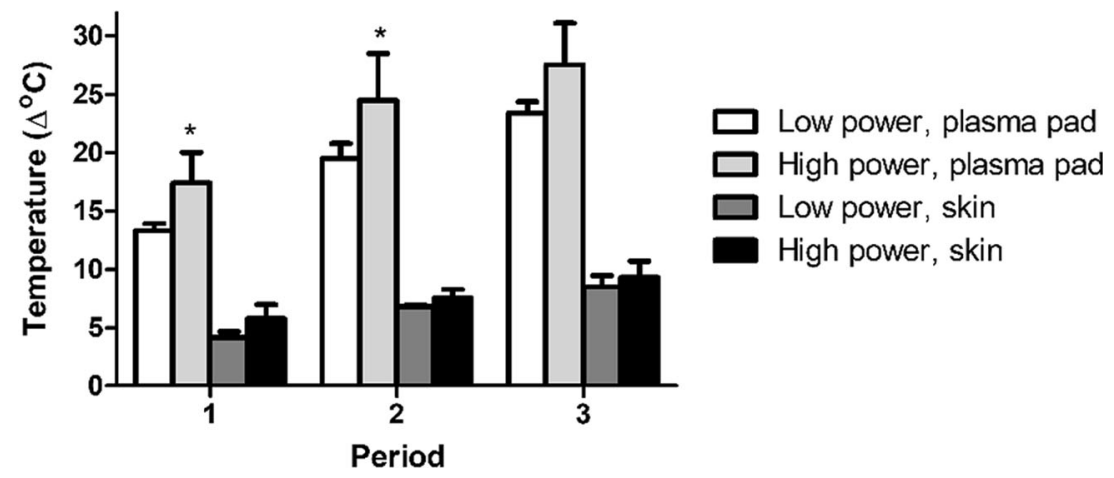

Fig. 5 Relative increase in temperature due to plasma treatment. Ex vivo skin was plasma treated for $3 \times 20 \mathrm{~s}$ and 2 intervals of $20 \mathrm{~s}$ with plasma off. Thermal images of pad and the skin were made directly at the end of

were included in this study; the demographics are shown in Table S1. Data generated from two subjects in group A were excluded from further analysis because plasma had not been produced, based on skin temperature and erythema. In group A, plasma was applied on the right arm at high power, and skin parameters were measured directly and $30 \mathrm{~min}$ after treatment. In group B and C, a bacterial suspension was placed on both arms. Plasma was applied on the right arm at high (group B) or low power (group C). After collecting the surviving bacteria from both arms, skin parameters were measured directly and $30 \mathrm{~min}$ after plasma treatment.

The following transient AEs (grade 1) were reported by the subjects: warmth sensation (all subjects) and itching until one day after treatment (1 subject in group A). SAEs did not occur.

The primary outcome pain estimated with NRS directly after CAP treatment was on average 3.3 (Table 1). All subjects indicated that the pain experienced during treatment was acceptable. Although pain scores were slightly lower in group C, pain scores were not significantly different between groups ( $p<0.05$, MWU). Pain scores were 0 after 30 min for all subjects.

Succesive Concentration Measurements With 1 Minute In Between

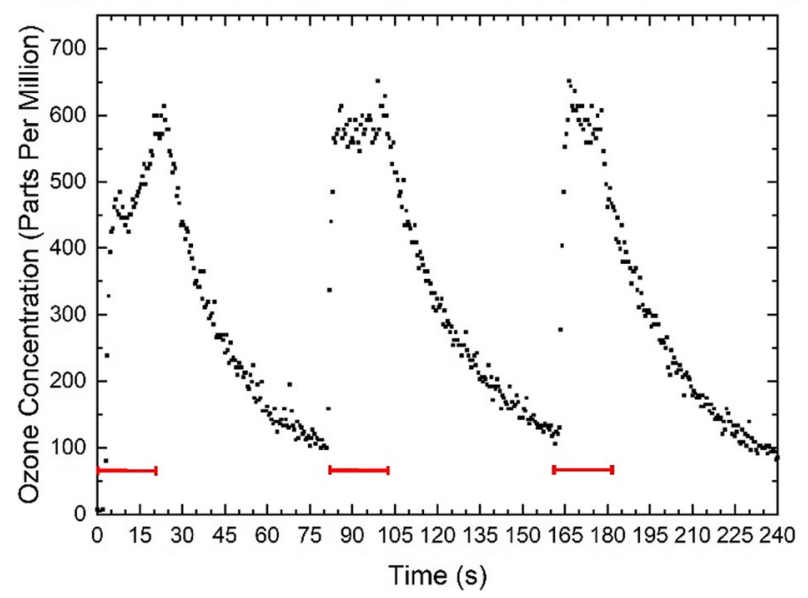

Fig. 6 Concentration of ozone produced by the plasma pad during three successive periods of $20 \mathrm{~s}$ (plasma on) separated by 60 -s intervals (plasma off). The red bars indicate when the plasma is on each period of $20 \mathrm{~s}$ of plasma on. Shown is the average temperature at the treatment area minus average temperature at the reference area in ${ }^{\circ} \mathrm{C} . *$ Significant difference compared to low plasma power, $p<0.05$ (MWU)

Baseline values were recorded on both inner volar arms. The mean absolute skin temperature at baseline was $32.0 \pm$ $3.8^{\circ} \mathrm{C}$. CAP treatment significantly increased local skin temperature by on average $3.4^{\circ} \mathrm{C}$ compared to baseline in all groups (Fig. 7a). After plasma application, skin temperature decreased and was similar to the reference area after $30 \mathrm{~min}$. No changes were observed in skin temperature on the left arm. Although mean skin temperature directly after CAP was slightly lower in group $\mathrm{C}$, significant differences between groups were not noted.

Plasma treatment also significantly increased the redness of the skin (Fig. 7B). Erythema index at baseline was on average 11 and increased with approximately $52 \%$ directly after plasma treatment in groups A and B ( $p<0.05$, WMP). The lower power setting in group $\mathrm{C}$ resulted in a significantly lower erythema index ( $8 \%$ increase) compared to the high power setting $(p<0.05$, MWU). Thirty minutes after treatment, erythema index of the treated arm was still significantly increased in all groups $(p<0.05$, WMP). No changes were observed in erythema index on the left arm.

TEWL measures the evaporation of water from the skin, which characterizes the barrier function of the stratum corneum. TEWL was significantly increased directly after treatment in all three groups (Fig. 7C). Because TEWL was also increased on the untreated contralateral arms (left), TEWL increase on the CAPtreated right arm was regarded as not related to plasma. Thirty minutes after the pads were removed, TEWL was still significantly increased in groups A (both arms) and C (left arm) $(p<0.05$, WMP). Significant differences between groups were not noted. TEWL after $30 \mathrm{~min}$ was lower on both arms in groups $\mathrm{B}$ and $\mathrm{C}$ than in group $\mathrm{A}$, which was most likely the result of the swabbing and cleaning procedure used to determine bacterial survival in groups $\mathrm{B}$ and $\mathrm{C}$.

\section{Antibacterial effect in healthy volunteers}

To study the bactericidal effect of CAP, the skin of both inner forearms of 15 volunteers (groups B and C) was contaminated 
Table 1 Primary outcome pain was assessed with NRS

\begin{tabular}{llllll}
\hline Group & $\mathrm{N}$ & Pain directly after plasma & Range & Tolerable & Pain 30 min after plasma \\
\hline A & 8 & $4.0 \pm 2.4$ & $0-7$ & $100 \%$ & 0 \\
B & 8 & $3.3 \pm 1.7$ & $1-6$ & $100 \%$ & 0 \\
C & 7 & $2.4 \pm 1.8$ & $0-5$ & $100 \%$ & 0 \\
All & 23 & $3.3 \pm 2.0$ & $0-7$ & $100 \%$ & 0 \\
\hline
\end{tabular}

Mean \pm standard deviation, range and tolerability are shown
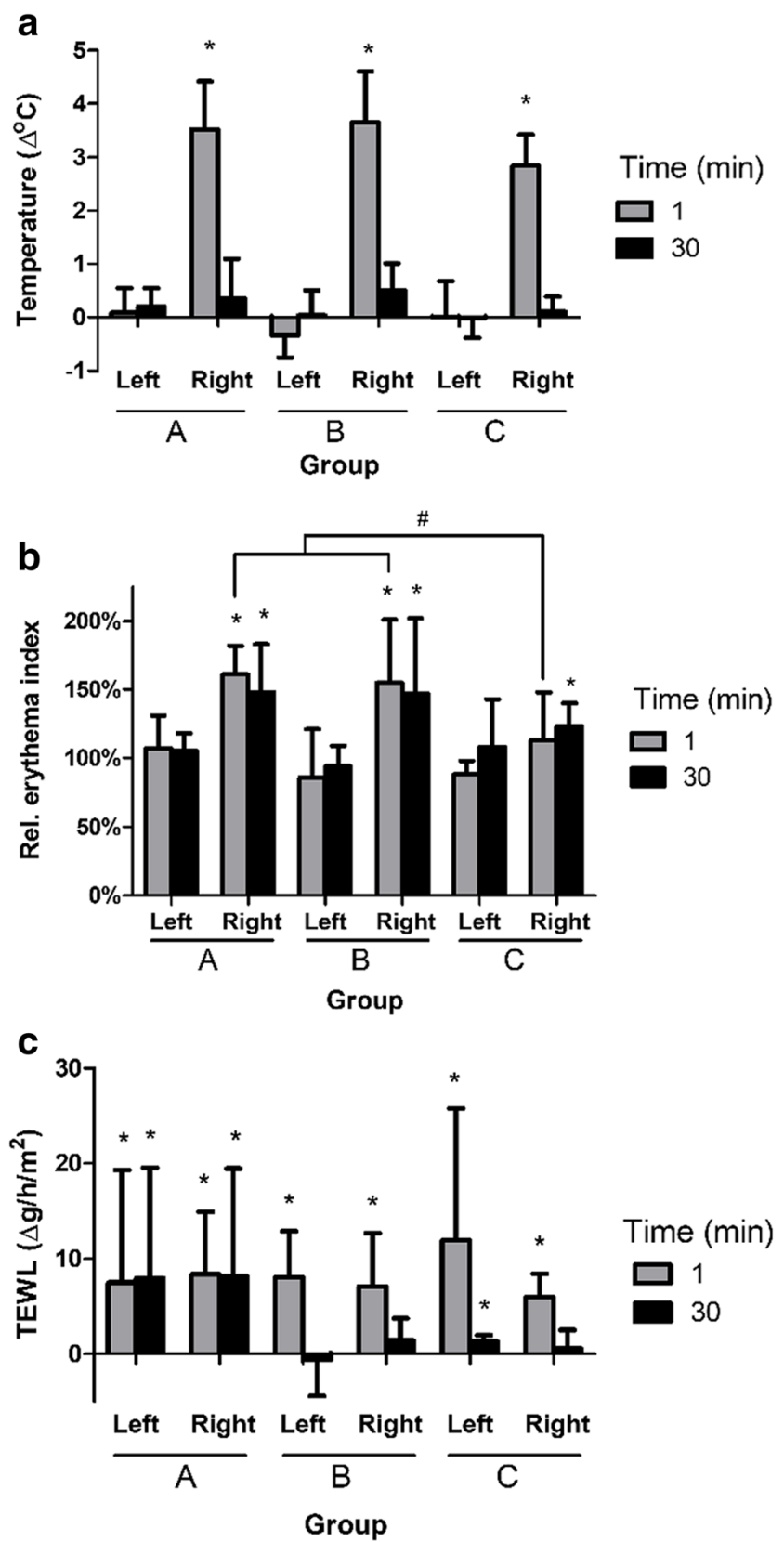

Fig. 7 a Relative skin temperature due to plasma treatment. Shown is the average skin temperature at the treatment area minus average skin temperature at baseline in ${ }^{\circ} \mathrm{C}$. $\mathbf{b}$ Erythema index relative to baseline. $\mathbf{c}$ TEWL values relative to baseline. Mean values and standard deviation directly (1) or $30 \mathrm{~min}$ after plasma treatment are shown. Left was the untreated arm, and right was the plasma treated arm. * Significant difference versus baseline, $p<0.05$ (WMP). \# Significant difference between indicated groups, $p<0.05$ (MWU) with $P$. aeruginosa. CAP was only applied to the area on the right arms. Surviving bacteria were collected from both arms by scrub wash and counted after plating. Data from one subject were excluded because of low bacterial survival on the untreated left arm. CAP significantly reduced the number of bacteria in both groups (Fig. 8). The mean log reduction was 2.9 and was not significantly affected by plasma power setting.

\section{Discussion}

In this study, we have shown the bactericidal property and safety of a flexible CAP device, both in vitro in wound models and in healthy volunteers on intact skin. Short plasma treatments were able to greatly reduce bacterial load and did not cause DNA damage or reduce cellular activity or wound healing.

The fast bactericidal effect of CAP was reduced by moisture and nature of the treated target such as skin vs. CEM (Fig. 2), which has been observed before. The skin was more difficult to

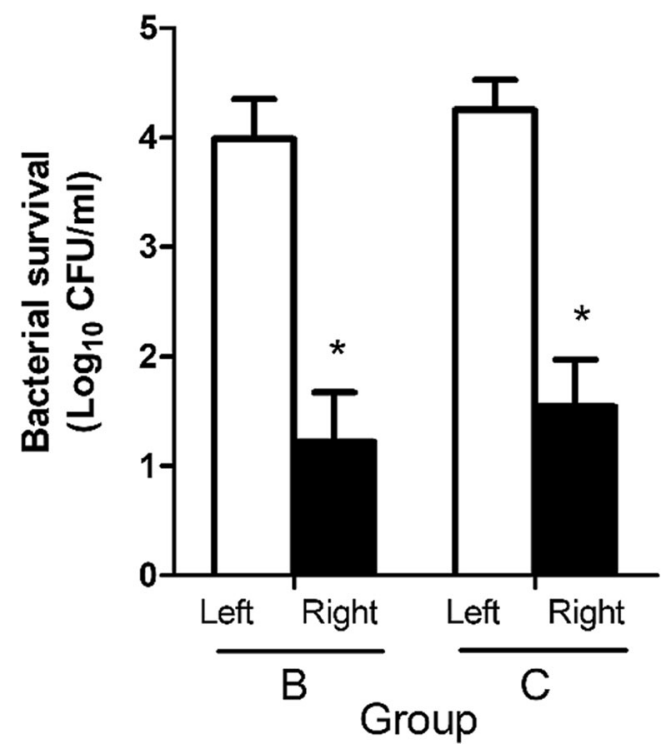

Fig. 8 Bacterial survival of $P$. aeruginosa PAO1 in Colony Forming Units (CFU), determined directly after plasma treatment for groups $\mathrm{B}$ and $\mathrm{C}$. Mean values and standard deviation are shown. Left was the untreated arm, and right was the plasma treated arm. * Significant difference of plasma treated (right) versus untreated control (left), $p<0.05$ (WMP). 
disinfect by CAP treatment than silicon or rubber (Pavlovich et al. 2013b). Humidity has been shown to be a critical factor for plasma inactivation of bacterial spores (Patil et al. 2014). The species responsible for bacterial killing (i.e. reactive oxygen or nitrogen species) might have reacted with other components present such as water and proteins of the skin.

One of the reactive species involved in CAP-mediated bacterial killing is ozone. Up to 600 ppm ozone was locally produced by the DBD plasma pads (Fig. 6). In contrast, jet-based plasma treatments exhibit low ozone production levels $(\approx 2$ ppm) (Zhang 2015; Zhang et al. 2013). Ozone has been reported to correlate with bacterial killing by a DBD device (Pavlovich et al. 2013a), and ozone was very effective against bacteria at 3-20 ppm in saline solution (Burgassi et al. 2009; Zeng et al. 2020), while $>100$ ppm was required when bacteria were present in diluted blood plasma (5-10\%) (Burgassi et al. 2009). High concentrations of ozone can however be a potential safety issue such as irritation of skin, eyes, and mucous membranes of the respiratory tract. Ozone may cause drowsiness, dizziness, headache, and fatigue. Limits for exposure via inhalation to ozone vary between 100 (guideline WHO) and 120 (guideline European Union) $\mu \mathrm{g} / \mathrm{m}^{3}$ for $8 \mathrm{~h}$ per day. The PLASOMA prototype produces $\approx 3 \mu \mathrm{g}$ ozone per 20 -s period, which does not pose a problem.

Single treatment with CAP for 120 s slightly reduced the cellular activity in dermal samples to $86 \%$ (Fig. 3), while $70 \%$ is the cut off for moderate toxicity (ISO10993-5 2015). Similar tests with different types of DBD devices have been performed on cells or skin in vitro (Awakowicz et al. 2009; Boekema et al. 2016; Dijksteel et al. 2020; Heuer et al. 2015; Isbary et al. 2013a; Laurita et al. 2017; Maisch et al. 2012) or in vivo (Rajasekaran et al. 2011; Wu et al. 2013), and the results on cellular activity, inflammation or DNA damage were found to be within safe limits. In addition, repeated CAP treatment with the PLASOMA prototype did not significantly lower activity of cells in dermal samples (Fig. 3) and did not affect epidermal regeneration or DNA integrity in human burn wound models (Fig. 4), which underscores the safety of CAP treatment. It is important to note that in these samples there is no blood flow or influx of cells as in the human body, which can affect heat transfer and healing rate. Repeated or extended exposure to CAP might result in an accumulation of cell damage. In the literature, repeated in vitro CAP treatments on tissue samples or cell cultures have not been described. However, in animal and clinical studies, repeated CAP treatments have been shown to be safe (Kisch et al. 2016b; Metelmann et al. 2012; van der Linde et al. 2017). Taken together, in vitro CAP treatment with the PLASOMA prototype for 1 or 2 min was effective and safe.

A systematic review showed that plasma treatment in general was safe (Assadian et al. 2019). Treatment with the here tested PLASOMA prototype was found to be safe in a study where patients with DFU received 10 treatments in 2 weeks on consecutive business days. After treatment of 20 patients, the median decrease in wound size was $55 \%$, and two wounds were completely healed after 2 weeks of treatment (Peters et al. 2017). The limited pain sensation reported by these DFU patients (slight pain in 5 out of 193 treatments) could be related to the underlying neuropathy leading to greatly diminished sensitivity (Volmer-Thole and Lobmann 2016). Before initiating a clinical study involving burn patients, we therefore determined safety and efficacy of the PLASOMA prototype in healthy volunteers. Subjects indicated that some transient, moderate pain was experienced during CAP treatment, with a mean score on the NRS of 3.3 (Table 1). All subjects rated the treatment acceptable despite several high NRS values. In studies where pain due to plasma treatment was scored with a visual analogue scale, a similar range of pain score (i.e. 0-5) was reported (Brehmer et al. 2015; Daeschlein et al. 2015b; Daeschlein et al. 2012a; Daeschlein et al. 2012b; Kisch et al. 2016a; Kisch et al. 2016b; Preissner et al. 2016).

Although referred to as cold or low temperature, CAP transiently increased the mean temperature of ex vivo skin with $9^{\circ} \mathrm{C}$ (Fig. 5) and of the skin in healthy volunteers with $3.4^{\circ} \mathrm{C}$ (Fig. 7a). The latter translates to an absolute skin temperature of $35.5^{\circ} \mathrm{C} \pm 3.4^{\circ} \mathrm{C}$ after removal of the pad. The lower increase in skin temperature in volunteers due to CAP treatment is probably related to heat transfer to the surrounding tissues and via blood circulation. Importantly, higher pain scores did not correlate with higher skin temperatures. Similar results have been reported in other studies. Plasma increased the skin temperature with $2^{\circ} \mathrm{C}$ (Borchardt et al. 2017; Fluhr et al. 2012) or resulted in a sensation of heat score of $0-5$ (Daeschlein et al. 2012a; Daeschlein et al. 2012b). Application of $42^{\circ} \mathrm{C}$ for 30 seconds could be well tolerated by volunteers (Oliveira et al. 2014) and stimulated blood flow, while fast heating resulted in a higher endothelial activity (Del Pozzi et al. 2016; Hodges et al. 2017). Natural cooling by exposure to ambient air quickly normalized blood flow (Wu et al. 2017). Natural cooling did not restore erythema index in our study, which indicates that this was not caused by the heat of the plasma. After applying external heat to the forearm of subjects, the mean thermal threshold for pain was approximately $47^{\circ} \mathrm{C}$ (Yosipovitch et al. 2004). In another study, pain at threshold temperature (median $44^{\circ} \mathrm{C}$ ) was scored 4.5 (median NRS) (Wasner and Brock 2008). To thermally kill bacteria on the skin, a temperature of $60^{\circ} \mathrm{C}$ for $30 \mathrm{~min}$ is required (Tsuji et al. 1982). Since the increase in skin temperature was only $3.4^{\circ} \mathrm{C}$ (Fig. 7a) and treatment time was short, the effect of heat on bacterial inactivation can be excluded.

CAP application with the PLASOMA prototype induced a significant but transient increase in erythema index. The erythema index is proportional to the haemoglobin content of the upper layers of the dermis and thus might be considered an indirect measure for microcirculation, although in scars a 
correlation between microcirculation as measured by laser Doppler imaging and erythema was not found (Jaspers et al. 2017b). Plasma can stimulate microcirculation of healthy skin beyond the treatment time (Borchardt et al. 2017; Fluhr et al. 2012; Heuer et al. 2015; Kisch et al. 2016a; Kisch et al. 2016b), which can improve the healing potential especially of chronic wounds. The enhanced microcirculation is probably mediated by plasma-produced nitric oxide (NO) (Heuer et al. 2015), which easily penetrates the skin (Ganzarolli de Oliveira 2016; Vercelino et al. 2013). The potential role of plasma-generated NO in medicine is discussed by Suschek et al. (Suschek and Opländer 2016). NO is an important messenger and regulator of blood flow, immune response and wound healing, and NO can act as an anti-oxidant. Together these results on skin temperature and erythema suggest that the applied CAP induced a transient increase in microcirculation through the action of heating and possibly NO.

The barrier function of skin was probed by measuring the Trans Epidermal Water Loss (TEWL). Application of CAP or heat will result in vasodilation and increased TEWL. Because TEWL values were increased in both arms in our study, this was most likely related to the temporary occlusion by the pad and not to the CAP treatment. TEWL values returned to normal levels after $30 \mathrm{~min}$ in groups $\mathrm{B}$ and $\mathrm{C}$, which was probably related to the swabbing and cleaning procedure used to determine bacterial survival. The reason for the sustained high TEWL levels in group A of our study remains elusive. Literature reports on TEWL related to plasma treatment are inconclusive: TEWL values were reduced by pulsed plasma jet and DBD by about 20\% (Daeschlein et al. 2012a) or were increased by plasma jet with $50 \%$ (Fluhr et al. 2012) due to plasma treatment.

Plasma is highly bactericidal in vitro, which has been shown for various plasma sources in many papers. Several studies have tested the bactericidal effect of plasma generated by DBD (Daeschlein et al. 2012b; Li et al. 2013) or jet (Julák and Scholtz 2013; Lademann et al. 2012) devices for medical use on intact skin. Significant bacterial log reductions ranging from 0.3 to 2.7 were obtained after treatment times ranging from a few seconds to $10 \mathrm{~min}$. After analysis of five clinical trials in a systematic review, CAP with DBD or jet demonstrated no significant reduction of bioburden in wounds (OR=0.85, $p=0.63$ ) (Assadian et al. 2019). Here we tested a DBD device on intact skin of volunteers that was contaminated with $P$. aeruginosa. We obtained a significant bacterial log reduction of 2.9 after a 1-min treatment. Bacteria on intact skin are more easily killed than bacteria in wounds, where blood, exudate and cellular material may limit the bactericidal effect especially when bacteria are present in a biofilm.

The power setting of the PLASOMA prototype did not affect the increase in temperature of ex vivo skin after CAP treatment. In healthy volunteers, the low power setting resulted in significantly less erythema and in trends towards lower skin temperature and less pain. Similar results were seen in mouse experiments where lowering the power of the plasma jet eliminated (or reduced) the temperature effect (Chatraie et al. 2018). Although lowering the power settings might reduce the disinfecting abilities of plasma devices (Zheng et al. 2016), the mean LR in our study was not significantly affected (Fig. 8).

This study has several limitations. We have treated only a small number of subjects, especially when comparing two power settings. Technical problems with this prototype device, i.e. device error or no plasma, occurred in many cases when treating volunteers and could be solved after repeated attempts to generate plasma. Device deficiency did not lead to a (S)AE; device errors were generated when the safety circuit of the device intervened. Nevertheless, short CAP applications were found safe and demonstrated good bactericidal properties.

Supplementary Information The online version contains supplementary material available at https://doi.org/10.1007/s00253-021-11166-5.

Acknowledgements We thank Bas Zeper and Paulien Smits of Plasmacure for providing the PLASOMA prototype and for fruitful discussions. We thank Joey van Blanken and Laura Hazenoot, both postgraduate students of the Hogeschool Leiden (Leiden, the Netherlands), for their contribution to in vitro data acquisition.

Author contribution $\mathrm{BB}, \mathrm{AS}, \mathrm{MU}$ and $\mathrm{EM}$ conceived and designed the research. BB, MS, MV and JvL conducted experiments. BB analysed the data and wrote the manuscript. All authors read and approved the manuscript.

Funding This research was funded by the Dutch Burns Foundation, grant number 14.200, and by ZonMw, grant number 40-41200-98-9189.

Data availability The datasets generated during and/or analysed during the current study are available from the corresponding author on reasonable request.

\section{Declarations}

Ethics approval The study protocol was approved by the regional ethics committee of Noord-Holland, the Netherlands (reference number M016046), registered at clinicaltrials.gov (registration number NCT03007264, January 2, 2017). The study followed the tenets of the Declaration of Helsinki (52nd World Medical Association General Assembly, Edinburgh, Scotland, October 2000).

Competing interests The authors declare no competing interests.

Open Access This article is licensed under a Creative Commons Attribution 4.0 International License, which permits use, sharing, adaptation, distribution and reproduction in any medium or format, as long as you give appropriate credit to the original author(s) and the source, provide a link to the Creative Commons licence, and indicate if changes were made. The images or other third party material in this article are included in the article's Creative Commons licence, unless indicated otherwise in a credit line to the material. If material is not included in the article's 
Creative Commons licence and your intended use is not permitted by statutory regulation or exceeds the permitted use, you will need to obtain permission directly from the copyright holder. To view a copy of this licence, visit http://creativecommons.org/licenses/by/4.0/.

\section{References}

Assadian O, Ousey KJ, Daeschlein G, Kramer A, Parker C, Tanner J, Leaper DJ (2019) Effects and safety of atmospheric low-temperature plasma on bacterial reduction in chronic wounds and wound size reduction: a systematic review and meta-analysis. Int Wound J 16: 103-111. https://doi.org/10.1111/iwj.12999

Awakowicz P, Bibinov N, Born M, Busse B, Gesche R, Helmke A, Kaemling A, Kolb-Bachofen V, Kovacs R, Kuehn S, Liebmann J, Mertens N, Niemann U, Oplaender C, Porteanu HE, Scherer J, Suschek C, Vioel W, Wandke D (2009) Biological stimulation of the human skin applying health-promoting light and plasma sources. Contrib Plasma Phys 49:641-647. https://doi.org/10.1002/ctpp. 200910068

Boekema BKHL, Pool L, Ulrich MMW (2013) The effect of a honey based gel and silver sulphadiazine on bacterial infections of in vitro burn wounds. Burns 39:754-759. https://doi.org/10.1016/j.burns. 2012.09.008

Boekema BKHL, Vlig M, Guijt D, Hijnen K, Hofmann S, Smits P, Sobota A, van Veldhuizen EM, Bruggeman P, Middelkoop E (2016) A new flexible DBD device for treating infected wounds: in vitro and ex vivo evaluation and comparison with a RF argon plasma jet. J Phys D Appl Phys 49:044001. https://doi.org/10.1088/ 0022-3727/49/4/044001

Borchardt T, Ernst J, Helmke A, Tanyeli M, Schilling AF, Felmerer G, Viol W (2017) Effect of direct cold atmospheric plasma (diCAP) on microcirculation of intact skin in a controlled mechanical environment. Microcirculation 24:e12399. https://doi.org/10.1111/micc. 12399

Brehmer F, Haenssle HA, Daeschlein G, Ahmed R, Pfeiffer S, Gorlitz A, Simon D, Schon MP, Wandke D, Emmert S (2015) Alleviation of chronic venous leg ulcers with a hand-held dielectric barrier discharge plasma generator (PlasmaDerm((R)) VU-2010): results of a monocentric, two-armed, open, prospective, randomized and controlled trial (NCT01415622). J Eur Acad Dermatol Venereol 29: 148-155. https://doi.org/10.1111/jdv.12490

Burgassi S, Zanardi I, Travagli V, Montomoli E, Bocci V (2009) How much ozone bactericidal activity is compromised by plasma components? J Appl Microbiol 106:1715-1721. https://doi.org/10.1111/j. 1365-2672.2008.04141.x

Chatraie M, Torkaman G, Khani M, Salehi H, Shokri B (2018) In vivo study of non-invasive effects of non-thermal plasma in pressure ulcer treatment. Sci Rep 8:5621. https://doi.org/10.1038/s41598018-24049-Z

Chuangsuwanich A, Assadamongkol T, Boonyawan D (2016) The healing effect of low-temperature atmospheric-pressure plasma in pressure ulcer: a randomized controlled trial. Int J Low Extrem Wounds 15:313-319. https://doi.org/10.1177/1534734616665046

Coolen NA, Schouten KC, Boekema BKHL, Middelkoop E, Ulrich MMW (2010) Wound healing in a fetal, adult, and scar tissue model: a comparative study. Wound Repair Regen 18:291-301. https://doi. $\operatorname{org} / 10.1111 / \mathrm{j} .1524-475 X .2010 .00585 . \mathrm{x}$

Daeschlein G (2018) Antimicrobial Activity of Plasma. In: Metelmann HR, Von Woedtke T, Weltmann KD (eds) Comprehensive Clinical Plasma Medicine. Springer International Publishing, pp 113-125

Daeschlein G, Scholz S, Ahmed R, Majumdar A, von Woedtke T, Haase H, Niggemeier M, Kindel E, Brandenburg R, Weltmann KD, Junger M (2012a) Cold plasma is well-tolerated and does not disturb skin barrier or reduce skin moisture. J Dtsch Dermatol Ges 10:509-515. https://doi.org/10.1111/j.1610-0387.2012.07857.x

Daeschlein G, Scholz S, Ahmed R, von Woedtke T, Haase H, Niggemeier M, Kindel E, Brandenburg R, Weltmann KD, Juenger M (2012b) Skin decontamination by low-temperature atmospheric pressure plasma jet and dielectric barrier discharge plasma. J Hosp Infect 81:177-183. https://doi.org/10.1016/j.jhin.2012.02.012

Daeschlein G, Napp M, Lutze S, Arnold A, von Podewils S, Guembel D, Junger M (2015a) Skin and wound decontamination of multidrugresistant bacteria by cold atmospheric plasma coagulation. J Dtsch Dermatol Ges 13:143-150. https://doi.org/10.1111/ddg.12559

Daeschlein G, Napp M, von Podewils S, Scholz S, Arnold A, Emmert S, Haase H, Napp J, Spitzmueller R, Gumbel D, Junger M (2015b) Antimicrobial efficacy of a historical high-frequency plasma apparatus in comparison with 2 modern, cold atmospheric pressure plasma devices. Surg Innov 22:394-400. https://doi.org/10.1177/ 1553350615573584

de Jong AE, Bremer M, Hofland HW, Schuurmans MJ, Middelkoop E, van Loey NE (2015) The visual analogue thermometer and the graphic numeric rating scale: a comparison of self-report instruments for pain measurement in adults with burns. Burns 41:333340. https://doi.org/10.1016/j.burns.2014.07.002

Del Pozzi AT, Miller JT, Hodges GJ (2016) The effect of heating rate on the cutaneous vasomotion responses of forearm and leg skin in humans. Microvasc Res 105:77-84. https://doi.org/10.1016/j.mvr. 2016.01.004

Dijksteel GS, Ulrich MMW, Vlig M, Sobota A, Middelkoop E, Boekema B (2020) Safety and bactericidal efficacy of cold atmospheric plasma generated by a flexible surface Dielectric Barrier Discharge device against $P$ seudomonas aeruginosa in vitro and in vivo. Ann Clin Microbiol Antimicrob 19:37. https://doi.org/10.1186/s12941-02000381-z

Dokter J, Brusselaers N, Hendriks WD, Boxma H (2016) Bacteriological cultures on admission of the burn patient: to do or not to do, that's the question. Burns 42:421-427. https://doi.org/10.1016/j.burns.2015. 08.006

Draaijers LJ, Tempelman FR, Botman YA, Kreis RW, Middelkoop E, van Zuijlen PPM (2004) Colour evaluation in scars: tristimulus colorimeter, narrow-band simple reflectance meter or subjective evaluation? Burns 30:103-107. https://doi.org/10.1016/j.burns.2003.09. 029

Ehlbeck J, Schnabel U, Polak M, Winter J, von Woedtke T, Brandenburg R, von dem Hagen T, Weltmann KD (2011) Low temperature atmospheric pressure plasma sources for microbial decontamination. J Phys D Appl Phys 44:013002. https://doi.org/10.1088/0022-3727/ 44/1/013002

Fluhr JW, Sassning S, Lademann O, Darvin ME, Schanzer S, Kramer A, Richter H, Sterry W, Lademann J (2012) In vivo skin treatment with tissue-tolerable plasma influences skin physiology and antioxidant profile in human stratum corneum. Exp Dermatol 21:130-134. https://doi.org/10.1111/j.1600-0625.2011.01411.x

Ganzarolli de Oliveira M (2016) S-Nitrosothiols as Platforms for Topical Nitric Oxide Delivery. Basic Clin Pharmacol Toxicol 119(Suppl 3): 49-56. https://doi.org/10.1111/bcpt.12588

Gorshelev V, Serdyuchenko A, Weber M, Chehade W, Burrows JP (2014) High spectral resolution ozone absorption cross-sections Part 1: Measurements, data analysis and comparison with previous measurements around 293K. In: Atmos Meas Tech 7(2):609-624. https://doi.org/10.5194/amt-7-609-2014

Heuer K, Hoffmanns MA, Demir E, Baldus S, Volkmar CM, Rohle M, Fuchs PC, Awakowicz P, Suschek CV, Oplander C (2015) The topical use of non-thermal dielectric barrier discharge (DBD): nitric oxide related effects on human skin. Nitric Oxide 44:52-60. https:// doi.org/10.1016/j.niox.2014.11.015

Hodges GJ, Mallette MM, Tew GA, Saxton JM, Moss J, Ruddock AD, Klonizakis M (2017) Effect of age on cutaneous vasomotor 
responses during local skin heating. Microvasc Res 112:47-52. https://doi.org/10.1016/j.mvr.2017.03.002

Isbary G, Morfill G, Schmidt HU, Georgi M, Ramrath K, Heinlin J, Karrer S, Landthaler M, Shimizu T, Steffes B, Bunk W, Monetti R, Zimmermann JL, Pompl R, Stolz W (2010) A first prospective randomized controlled trial to decrease bacterial load using cold atmospheric argon plasma on chronic wounds in patients. Br J Dermatol 163:78-82. https://doi.org/10.1111/j.1365-2133.2010. 09744.x

Isbary G, Heinlin J, Shimizu T, Zimmermann JL, Morfill G, Schmidt HU, Monetti R, Steffes B, Bunk W, Li Y, Klaempfl T, Karrer S, Landthaler M, Stolz W (2012) Successful and safe use of 2 min cold atmospheric argon plasma in chronic wounds: results of a randomized controlled trial. Br J Dermatol 167:404-410. https://doi.org/10. 1111/j.1365-2133.2012.10923.x

Isbary G, Köritzer J, Mitra A, Li YF, Shimizu T, Schroeder J, Schlegel J, Morfill GE, Stolz W, Zimmermann JL (2013a) Ex vivo human skin experiments for the evaluation of safety of new cold atmospheric plasma devices. Clin Plasma Med 1:36-44. https://doi.org/10.1016/ j.cpme.2012.10.001

Isbary G, Stolz W, Shimizu T, Monetti R, Bunk W, Schmidt HU, Morfill GE, Klämpfl TG, Steffes B, Thomas HM, Heinlin J, Karrer S, Landthaler M, Zimmermann JL (2013b) Cold atmospheric argon plasma treatment may accelerate wound healing in chronic wounds: results of an open retrospective randomized controlled study in vivo. Clin Plasma Med 1:25-30

ISO10993-5 (2015) Biological evaluation of medical devices - Part 5: Tests for in vitro cytotoxicity ISO 10993-5:2015-02

Jaspers MEH, Carriere ME, Meij-de Vries A, Klaessens J, van Zuijlen PPM (2017a) The FLIR ONE thermal imager for the assessment of burn wounds: reliability and validity study. Burns 43:1516-1523. https://doi.org/10.1016/j.burns.2017.04.006

Jaspers MEH, Stekelenburg CM, Simons JM, Brouwer KM, Vlig M, van den Kerckhove E, Middelkoop E, van Zuijlen PPM (2017b) Assessing blood flow, microvasculature, erythema and redness in hypertrophic scars: a cross sectional study showing different features that require precise definitions. Burns 43:1044-1050. https://doi. org/10.1016/j.burns.2017.01.017

Julák J, Scholtz V (2013) Decontamination of human skin by lowtemperature plasma produced by cometary discharge. Clin Plasma Med 1:31-34. https://doi.org/10.1016/j.cpme.2013.09.002

Kisch T, Helmke A, Schleusser S, Song J, Liodaki E, Stang FH, Mailaender P, Kraemer R (2016a) Improvement of cutaneous microcirculation by cold atmospheric plasma (CAP): results of a controlled, prospective cohort study. Microvasc Res 104:55-62. https:// doi.org/10.1016/j.mvr.2015.12.002

Kisch T, Schleusser S, Helmke A, Mauss KL, Wenzel ET, Hasemann B, Mailaender P, Kraemer R (2016b) The repetitive use of non-thermal dielectric barrier discharge plasma boosts cutaneous microcirculatory effects. Microvasc Res 106:8-13. https://doi.org/10.1016/j.mvr. 2016.02.008

Klebes M, Ulrich C, Kluschke F, Patzelt A, Vandersee S, Richter H, Bob A, von Hutten J, Krediet JT, Kramer A, Lademann J, LangeAsschenfeld B (2015) Combined antibacterial effects of tissuetolerable plasma and a modern conventional liquid antiseptic on chronic wound treatment. J Biophotonics 8:382-391. https://doi. org/10.1002/jbio.201400007

Kuo LJ, Yang LX (2008) Gamma-H2AX - a novel biomarker for DNA double-strand breaks. In Vivo 22:305-309

Lademann J, Richter H, Schanzer S, Patzelt A, Thiede G, Kramer A, Weltmann KD, Hartmann B, Lange-Asschenfeldt B (2012) Comparison of the antiseptic efficacy of tissue-tolerable plasma and an octenidine hydrochloride-based wound antiseptic on human skin. Skin Pharmacol Physiol 25:100-106. https://doi.org/10.1159/ 000335558
Laurita R, Miserocchi A, Ghetti M, Gherardi M, Stancampiano A, Purpura V, Melandri D, Minghetti P, Bondioli E, Colombo V (2017) Cold atmospheric plasma treatment of infected skin tissue: evaluation of sterility, viability, and integrity. IEEE Trans Rad Plasma Med Sci 1:275-279. https://doi.org/10.1109/trpms.2017. 2679010

Li L, Gu W, Du J, Reid B, Deng X, Liu Z, Zong Z, Wang H, Yao B, Yang C, Yan J, Zeng L, Chalmer L, Zhao M, Jiang J (2012) Electric fields guide migration of epidermal stem cells and promote skin wound healing. Wound Repair Regen 20:840-851. https://doi.org/10.1111/ j.1524-475X.2012.00829.X

Li YF, Taylor D, Zimmermann JL, Bunk W, Monetti R, Isbary G, Boxhammer V, Schmidt HU, Shimizu T, Thomas HM, Morfill GE (2013) In vivo skin treatment using two portable plasma devices: comparison of a direct and an indirect cold atmospheric plasma treatment. Clin Plasma Med 1:35-39. https://doi.org/10.1016/j. cpme.2013.09.001

Maisch T, Shimizu T, Li YF, Heinlin J, Karrer S, Morfill G, Zimmermann JL (2012) Decolonisation of MRSA, S. aureus and E. coli by coldatmospheric plasma using a porcine skin model in vitro. PLoS One 7:e34610. https://doi.org/10.1371/journal.pone.0034610

Metelmann H-R, von Woedtke T, Bussiahn R, Weltmann K-D, Rieck M, Khalili R, Podmelle F, Waite PD (2012) Experimental recovery of CO2-laser skin lesions by plasma stimulation. Am J Cosmet Surg 29:52-56. https://doi.org/10.5992/ajcs-d-11-00042.1

Oliveira G, Leverett JC, Emamzadeh M, Lane ME (2014) The effects of heat on skin barrier function and in vivo dermal absorption. Int $\mathrm{J}$ Pharm 464:145-151. https://doi.org/10.1016/j.ijpharm.2014.01.012

Patil S, Moiseev T, Misra NN, Cullen PJ, Mosnier JP, Keener KM, Bourke $P$ (2014) Influence of high voltage atmospheric cold plasma process parameters and role of relative humidity on inactivation of Bacillus atrophaeus spores inside a sealed package. J Hosp Infect 88:162-169. https://doi.org/10.1016/j.jhin.2014.08.009

Pavlovich MJ, Chang HW, Sakiyama Y, Clark DS, Graves DB (2013a) Ozone correlates with antibacterial effects from indirect air dielectric barrier discharge treatment of water. J Phys D Appl Phys 46: 145202. https://doi.org/10.1088/0022-3727/46/14/145202

Pavlovich MJ, Chen Z, Sakiyama Y, Clark DS, Graves DB (2013b) Effect of discharge parameters and surface characteristics on ambient-gas plasma disinfection. Plasma Process Polym 10:69-76. https://doi.org/10.1002/ppap.201200073

Peters EJ, Lagrand R, Smits P, Pemen G, Sobota A, Zeper B, Sabel LW (2017) Cold atmospheric pressure plasma as a novel treatment modality in diabetic foot ulcers - a pilot study. In: EWMA, vol 67. American Diabetes Association, Amsterdam, 2018, p LB12

Preissner S, Kastner I, Schutte E, Hartwig S, Schmidt-Westhausen AM, Paris S, Preissner R, Hertel M (2016) Adjuvant antifungal therapy using tissue tolerable plasma on oral mucosa and removable dentures in oral candidiasis patients: a randomised double-blinded splitmouth pilot study. Mycoses 59:467-475. https://doi.org/10.1111/ myc. 12495

Rajasekaran P, Opländer C, Hoffmeister D, Bibinov N, Suschek CV, Wandke D, Awakowicz P (2011) Characterization of dielectric barrier discharge (DBD) on mouse and histological evaluation of the plasma-treated tissue. Plasma Process Polym 8:246-255. https://doi. org/10.1002/ppap.201000122

Rogiers V (2001) EEMCO guidance for the assessment of transepidermal water loss in cosmetic sciences. Skin Pharmacol Appl Ski Physiol 14:117-128. https://doi.org/10.1159/000056341

Suschek CV, Opländer C (2016) The application of cold atmospheric plasma in medicine: the potential role of nitric oxide in plasmainduced effects. Clin Plasma Med 4:1-8. https://doi.org/10.1016/j. cpme.2016.05.001

Tagami H, Yoshikuni K (1985) Interrelationship between water-barrier and reservoir functions of pathologic stratum corneum. Arch 
Dermatol 121:642-645. https://doi.org/10.1001/archderm.1985. 01660050094022

Taylor D, Daulby A, Grimshaw S, James G, Mercer J, Vaziri S (2003) Characterization of the microflora of the human axilla. Int J Cosmet Sci 25:137-145. https://doi.org/10.1046/j.1467-2494.2003.00181.x

Tiede R, Emmert S, Isbary G (2018) Treatment of ulcerations and wounds. In: Metelmann HR, Von Woedtke T, Weltmann KD (eds) Comprehensive Clinical Plasma Medicine. Springer, Cham, pp 127-149

Tsuji A, Kaneko Y, Takahashi K, Ogawa M, Goto S (1982) The effects of temperature and $\mathrm{pH}$ on the growth of eight enteric and nine glucose non-fermenting species of gram-negative rods. Microbiol Immunol $26: 15-24$

Ulrich C, Kluschke F, Patzelt A, Vandersee S, Czaika VA, Richter H, Bob A, Hutten J, Painsi C, Huge R, Kramer A, Assadian O, Lademann J, Lange-Asschenfeldt B (2015) Clinical use of cold atmospheric pressure argon plasma in chronic leg ulcers: a pilot study. J Wound Care 24:196-203. https://doi.org/10.12968/jowc.2015.24. 5.196

van der Linde J, Liedtke KR, Matthes R, Kramer A, Heidecke CD, Partecke LI (2017) Repeated cold atmospheric plasma application to intact skin does not cause sensitization in a standardized murine model. Plasma Med 7:383-393. https://doi.org/10.1615/ PlasmaMed.2017019167

Vercelino R, Cunha TM, Ferreira ES, Cunha FQ, Ferreira SH, de Oliveira MG (2013) Skin vasodilation and analgesic effect of a topical nitric oxide-releasing hydrogel. J Mater Sci Mater Med 24:2157-2169. https://doi.org/10.1007/s10856-013-4973-7

Volmer-Thole M, Lobmann R (2016) Neuropathy and diabetic foot syndrome. Int J Mol Sci 17:917. https://doi.org/10.3390/ijms17060917

Wasner GL, Brock JA (2008) Determinants of thermal pain thresholds in normal subjects. Clin Neurophysiol 119:2389-2395. https://doi.org/ 10.1016/j.clinph.2008.07.223

Wu AS, Kalghatgi S, Dobrynin D, Sensenig R, Cerchar E, Podolsky E, Dulaimi E, Paff M, Wasko K, Arjunan KP, Garcia K, Fridman G, Balasubramanian M, Ownbey R, Barbee KA, Fridman A, Friedman G, Joshi SG, Brooks AD (2013) Porcine intact and wounded skin responses to atmospheric nonthermal plasma. J Surg Res 179:e1e12. https://doi.org/10.1016/j.jss.2012.02.039

Wu Y, Nieuwenhoff MD, Huygen FJ, van der Helm FC, Niehof S, Schouten AC (2017) Characterizing human skin blood flow regulation in response to different local skin temperature perturbations. Microvasc Res 111:96-102. https://doi.org/10.1016/j.mvr.2016.12. 007

Yosipovitch G, Meredith G, Chan YH, Goh CL (2004) Do ethnicity and gender have an impact on pain thresholds in minor dermatologic procedures? A study on thermal pain perception thresholds in Asian ethnic groups. Skin Res Technol 10:38-42. https://doi.org/ 10.1111/j.1600-0846.2004.00051.x

Zeng J, Dou J, Gao L, Xiang Y, Huang J, Ding S, Chen J, Zeng Q, Luo Z, Tan W, Lu J (2020) Topical ozone therapy restores microbiome diversity in atopic dermatitis. Int Immunopharmacol 80:106191. https://doi.org/10.1016/j.intimp.2020.106191

Zhang S (2015) Atmospheric pressure RF plasma jet: characterization of flow and $\mathrm{O} 2$ chemistry. PhD Thesis, Eindhoven University of Technology

Zhang S, van Gaens W, van Gessel B, Hofmann S, van Veldhuizen E, Bogaerts A, Bruggeman PJ (2013) Spatially resolved ozone densities and gas temperatures in a time modulated RF driven atmospheric pressure plasma jet: an analysis of the production and destruction mechanisms. J Phys D Appl Phys 46:205202

Zheng C, Kou Y, Liu Z, Li C, Huang Y, Yan K (2016) Rapid disinfection performance of a touchable pulsed SDBD nonthermal plasma. IEEE Plasma Sci 44:2667-2672. https://doi.org/10.1109/tps.2016. 2576558

Zimmermann JL, Shimizu T, Schmidt HU, Li YF, Morfill GE, Isbary G (2012) Test for bacterial resistance build-up against plasma treatment. New J Phys 14:073037. https://doi.org/10.1088/1367-2630/ $14 / 7 / 073037$

Publisher's note Springer Nature remains neutral with regard to jurisdictional claims in published maps and institutional affiliations. 